\title{
New Experimental Setup Design for Applying Physical Blowing Agent in Rapid Rotational Foam Molding Technology
}

\author{
Isha Raktim \\ Faculty of Engineering and Applied Science \\ University of Ontario Institute of Technology \\ Oshawa, Canada
}

\author{
Remon Pop-Iliev \\ Faculty of Engineering and Applied Science \\ University of Ontario Institute of Technology \\ Oshawa, Canada
}

\begin{abstract}
This paper presents a manufacturing process for extrusion assisted foam production with a physical blowing agent (PBA) for Rapid Rotational Foam Molding. A completely new experimental setup was designed to identify, conceive, establish, and develop, the necessary processing concepts and conditions for fabricating a new class of rotationally molded integral-skin cellular composite having low-density foamed core. The new design incorporates a helical static mixer that can operate at $31 \mathrm{MPa}$ in $200^{\circ} \mathrm{C}$ environment. Supercritical $\mathrm{CO}_{2}$ will be injected into the pressurized static mixer to thoroughly disassociate into the polymer melt to create a single-phase solution. The process temperature is maintained by PID controlled band heaters and an integral liquid cooling jacket. The system can facilitate rapid pressure drop as high as $30 \mathrm{MPa}$ to produce polyolefin foam.
\end{abstract}

Keywords; helical; static mixer; RRFM; PBA; Polyolefin; supercritical fluid; QFD; carbon dioxide

\section{INTRODUCTION}

Rotational molding technology has been in use for the last few decades to produce light weight structural foam composites with a distinct foamed core encapsulated by an unfoamed outer skin. This type of roto-molded articles are in high demand in the automotive, construction and marine industries for their enhanced strength-to-weight ratio $[1,2]$. However, the manufacturing process associated with rotational molding is lengthy and highly energy intensive. In recent years a newly patented rotational foam molding process, referred to as Rapid Rotational Foam Molding (RRFM) was developed to reduce the lengthy production time and to improve the overall quality of the foamed composites [3, 4].

The RRFM technology by design produces the outer skin independent from the foaming process. This novel processing concept takes advantage of an extruder to produce the polymer foam, which is directly injected inside the hot mold cavity containing the soft outer skin. The foamed core encapsulated by the outer skin is gradually cooled to room temperature before extracting the final part from the mold. Through greater control over the manufacturing process, RRFM technology has reduced the cycle time and energy consumption compared with traditional rotational foam molding process [3].

In the current art, RRFM process is open to further improvement. The technology can be modified in two areas, rotational molding process, or the foam extrusion process.
However, the foam extrusion process shows greater potential for improvement. Currently the polymer foam is created using chemical blowing agents (CBA). The foamable resin is mixed in with the CBA before introducing the mixture into the extruder. In the extruder the CBA activates to produce the polymer foam. An alternative approach to this process is to produce the foam using a physical blowing agent (PBA). Polymer foaming with a PBA for rotational foam molding has never been attempted. Plastic foam produced with PBA have higher cell density which can further improve the strength-to- weight ratio [5]. Therefore, it is the next logical step in development to replace CBA with PBA for processing polyolefin integral-skin composites with RRFM.

The principal objective of the presently presented research is to design and develop an experimental setup that would enable testing and verification of novel processing concepts that would improve further melt extrusion-assisted rotational foam molding operations. In this context, the existing lab-scale rapid rotational foam molding experimental setup will have to be modified to introduce a physical blowing agent.

\section{CONCEPT GENERATION}

The RRFM experimental setup consists of a rotational arm assembly; mold translation system; convection oven and the extruder assembly (Fig. 1). The new modification will be applied to the extruder assembly to introduce PBA into the polymer melt. In the subsequent experiments, super critical carbon dioxide will be used as the blowing agent. $\mathrm{CO}_{2}$ is ideal for foaming application for having higher solubility in polymer melt compared to nitrogen gas. In this context, the foam produced from carbon dioxide is of a higher quality [6].

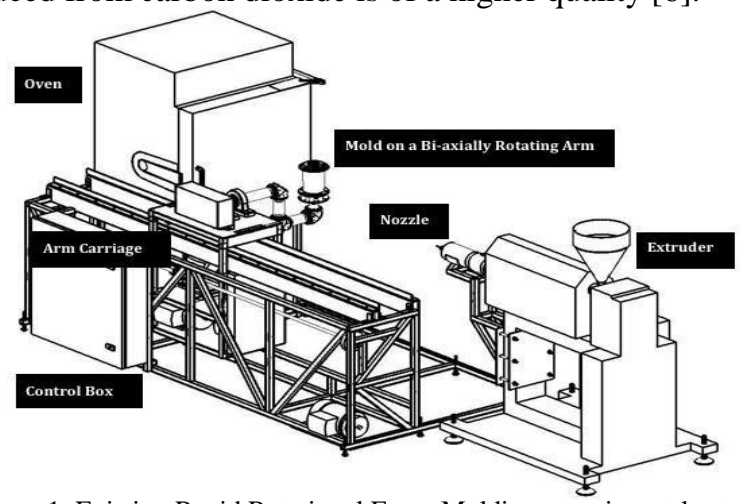

Figure 1. Existing Rapid Rotational Foam Molding experimental setup. 


\section{A. Design Selection Methodology}

It is important to identify the engineering specifications that are necessary for a good design. In the current state, the experimental setup is not equipped for PBA introduction. The goal is to design a system that can work efficiently with the existing extruder and produce foamed articles that are of equal or of a higher quality than RRFM foam composites. To identify the design requirements, a quality function deployment (QFD) tool was used. It translates general qualitative (non-specific) customer needs into engineering specifications for a new system design. Utilizing the house of quality (QFD tool), the most important engineering specifications were identified from the prospective of a customer. In this QFD assessment the primary customer is identified as a researcher in polymer processing industry. The strongest relationship between a customer requirement and the design parameters are identified in table I.

The identified design parameters are implemented in the concept generation phase. A decision matrix is used to select a system design from one of these concepts. The criteria for selection is based on the overall operation of each concept, rather than on each individual component. The importance of each criteria is assigned a value from 1 to 10 , where 10 is the most important criteria. One of the concept is selected as the datum to compare against the alternatives. A positive or a negative symbol is given on how well a criterion is satisfied under each concept against the datum (table II). The weighted total is tabulated for each concept by multiplying the symbol to each criteria rating. The concept with the highest weighted total is selected for the new system design.

\section{B. Concept Selection}

Each concept is represented in a simplified block diagram where all major components are identified in Fig. 2. The functional requirement for every concept is to achieve high degree of mixing between the polymer melt and supercritical $\mathrm{CO}_{2}$. It is through the mixing process where $\mathrm{CO}_{2}$ gas is dissolved into the polymer melt to produce a single-phase solution [7]. This process is controlled through manipulating the chamber pressure, temperature, and the flow rate of both gas and molten polymer. The dissolved $\mathrm{CO}_{2}$ gas within the molten polymer will produce the foam after experiencing a rapid pressure drop at the die exit. In order to understand the necessary processing condition for PBA application in RRFM technology, each concept presents a different foaming strategy for feasibility analysis.

a) Concept 1: In this experimental setup, the molten polymer is fed into a static mixer from the extruder. The melt pressure and the polymer flowrate are controlled by the screw RPM. The $\mathrm{CO}_{2}$ gas is injected into the static mixer chamber to begin the mixing process. The gas laden polymer melt moves down the static mixer barrel toward stationary mixing blades. These blades provide the mixing action through splitting the polymer flow and then recombining it to disassociate the $\mathrm{CO}_{2}$ gas into the polymer matrix. The temperature of the mixture is controlled by band heaters and an oil-based cooling jacket placed on the exterior shell. The final polymer solution is extruded out of the die where rapid drop in pressure produces the foam.

b) Concept 2: In this configuration, two extruders are placed in tandem seen in Fig. 2. The first extruder plasticizes the polymer resin and the second extruder is used to mix the $\mathrm{CO}_{2}$ gas. It is through the rotation of the second screw where vigorous shear mixing can be achieved [7]. The polymer/gas solution pressure and flowrate are controlled from the second extruder. However, the feedrate into the second extruder is controlled by the first one. Temperature of the gas laden polymer melt is maintained by PID controlled band heaters on the extruder barrel.

c) Concept 3: The final proposal is a modified version of concept 1 . In this setup, a gear pump is used to compensate for pressure loss incurred in the static mixer because of frictional losses at the blade surface. The pressure and flow rate can be controlled by both the gear pump and the extruder screw RPM. In the cooling system, water is used as the cooling fluid rather than oil.

The weighted total from the decision matrix is negative for concepts $2 \& 3$. Therefore, concept 1 will be used as the experimental setup for PBA application. Although concept 1 has lower degree of process control, it is more attractive for having fewer design and fabrication complexity than the alternatives. In regards to safety, concept 2 is better for having an integrated heating element housed within the extruder and thereby lowering the risk of contact with the operator. However this setup requires more lab space which makes it difficult for

TABLE I. QUALITY FUNCTION DEPLOYMENT ANALYSIS

\begin{tabular}{|c|c|c|}
\hline \multirow{2}{*}{ Customer } & \multicolumn{2}{|c|}{$\begin{array}{c}\text { Design Parameters from House of Quality } \\
\text { Assessment }\end{array}$} \\
\cline { 2 - 3 } & $\begin{array}{c}\text { Customer } \\
\text { Requirements }\end{array}$ & $\begin{array}{c}\text { Engineering } \\
\text { Specifications }\end{array}$ \\
\hline \multirow{4}{*}{ Researcher } & Homogenize \\
Mixing & $\begin{array}{c}\text { Gas solubility in polymer } \\
\text { melt; Heat Input; Screw } \\
\text { RPM; Blade geometry \& } \\
\text { length }\end{array}$ \\
\cline { 2 - 3 } & $\begin{array}{c}\text { Microcellular } \\
\text { bubble formation }\end{array}$ & $\begin{array}{c}\text { Screw RPM; Gas injection } \\
\text { pressure; Pressure drop }\end{array}$ \\
\cline { 2 - 3 } & \multicolumn{2}{|c|}{$\begin{array}{c}\text { Heat Input; Gas injection } \\
\text { pressure; Screw RPM; } \\
\text { Cooling fluid flowrate }\end{array}$} \\
\hline
\end{tabular}

TABLE II. CONCEPT FEAsIBILITy OF PBA APPLICATION

\begin{tabular}{|c|c|c|c|c|}
\hline \multirow[b]{2}{*}{ Criteria } & \multirow[b]{2}{*}{ Importance } & & \multicolumn{2}{|c|}{ Alternative } \\
\hline & & $\begin{array}{c}\text { Concept } \\
1\end{array}$ & $\begin{array}{c}\text { Concept } \\
2\end{array}$ & $\begin{array}{c}\text { Concept } \\
3\end{array}$ \\
\hline $\begin{array}{c}\text { Design } \\
\text { Complexity }\end{array}$ & 10 & \multirow{5}{*}{ Datum } & - & - \\
\hline $\begin{array}{c}\text { Process } \\
\text { Controllability }\end{array}$ & 9 & & + & + \\
\hline $\begin{array}{l}\text { Space Required } \\
\text { for Components }\end{array}$ & 7 & & - & - \\
\hline Safety & 8 & & + & - \\
\hline $\begin{array}{l}\text { Fabrication } \\
\text { Complexity }\end{array}$ & 9 & & - & - \\
\hline Weighted & otal & 0 & -9 & -25 \\
\hline
\end{tabular}


the operator to move around and use other equipment. Concept 2 is the least desirable in term of safety for having a water cooling system, where steam might be produced. Which will pose as a hazard for the operator by leaking out through small clearances in the pipefittings and connecting junctions. Steam has to be safely vented to stop pipe rupture. Also, when water turns to steam a liquid pump cannot pump it. Therefore, a cooling fluid with a high boiling point must be selected to prevent this problem. An oil-based cooling system will be implemented to provide all the cooling needs for the foam extrusion process.

\section{FINAL PBA EXPERIMENTAL SETUP DESIGN}

The newly modified lab-scale custom-build experimental setup must accomplish high degree of mixing between the $\mathrm{CO}_{2}$ gas and the polyolefin melt. A single-phase polymer-gas solution with homogeneity greater than $80 \%$ is desired. The pressure drop across the length of the mixing apparatus must not exceed the burst pressure of the extruder. The maximum allowable pressure drop should be limited 7 to $10 \mathrm{MPa}$.

\section{A. Design Guidelines}

The physical blowing agent $\left(\mathrm{CO}_{2}\right)$ will be injected directly into the static mixer at pressures between 20-30 MPa to mix with the melted polyolefin resin. For instance, $\mathrm{CO}_{2}$ is soluble in molten polyethylene at high pressure and it can act as a plasticizer. Static mixers have to be attached after the extruder to completely dissolve the gas solution into the polymer melt. The blade design of the static mixer must generate shear field to enhance gas disassociation. Rapid pressure drop will be initiated at the die exit to cause phase separation between the gas and polymer solution. This will cause the gas to bubble out of the solution creating polymer foam. The foam will be injected into the open mold to fill the mold's cavity on top of the hot skin as the mold is rotated in a single axis.

An optimal cooling rate must be established to ensure the generation of microcells and even cell distribution. A cooling system on the static mixer wall will be used to cool the mixture temperature near the die inlet. This will lower the gas solubility within the polymer matrix and this will initiate phase separation and cell nucleation.

\section{B. Static Mixer Chamber Design}

Static mixers provide advantages and disadvantages in polymer foam processing. Static mixers have static blades that replicate shear fields necessary for high degree of mixing. The geometry of the mixing elements reorients the flow in radial direction to enhance the mixing. Through this mixing process radial temperature gradient is eliminated, and wall-creep material is incorporated into the bulk polymer flow. A major disadvantage is the pressure loss across the length of the static mixer. The static mixer type and size are crucial to determine if the extruder can provide enough force to push the material through the mixing elements. Static mixers are installed in front of the extruder. Many types of arrangements are possible which depends on the specific application. Some industrial applications include, extrusion blow molding, foam sheet production, coextrusion and for blow film [8].
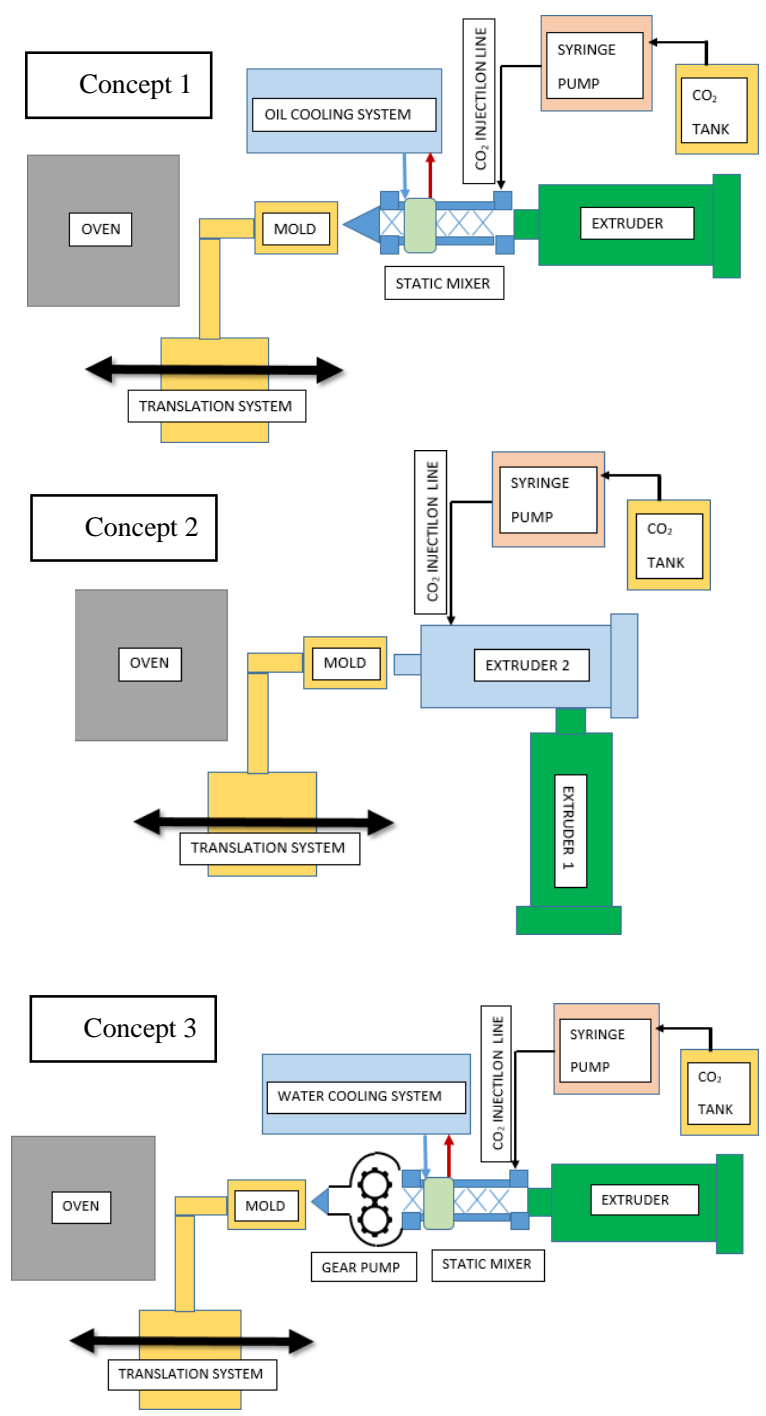

Figure 2. Possible Experimental setup for PBA Application.

The main purpose of the static mixer is to homogenize the melt upstream from the die exit. This is achieved through splitting the flow toward the radial direction and later rearranging the two split streams. The mixing elements are offset by $90^{\circ}$ to ensure uniform distribution. The pressure loss across the length of the static mixer is dependent on the polymer-melt viscosity, Reynolds number, mixing element geometry, and process temperature and polymer grade [8].

$$
\begin{gathered}
\Delta P=\left(\frac{4}{\pi}\right) \operatorname{NeRe}_{D}\left(\frac{\dot{V}}{D^{3}}\right) \eta\left(\frac{n_{M E}}{2}\right) . \\
\eta=f\left(\dot{\gamma}, T, \text { polymer }(\text { type }, \text { grade }), p_{o p} .\right. \\
\dot{\gamma}=f\left(\dot{V}, D_{M E}, \text { geometry }\right) .
\end{gathered}
$$

The pressure loss inside a static mixer is obtained from "(1)", where "NeRe $e_{D}$ " is the Reynolds number and " $\dot{V}$ " is the volumetric flow rate and " $n_{M E}$ " is the number of mixing elements and " $\eta$ " is the melt viscosity. The melt viscosity is obtained from "(2)", which is dependent on operating pressure, temperature, polymer type and shear rate " $\dot{\gamma}$ ". The shear rate "(3)" is a function of flow rate, and the mixing blade geometry. 
In relation to a grid mesh mixer, the Reynolds number can be between $1200 \& 2000$. However, inside a helical type mixer the Reynolds number is between $200 \& 400$.

Engineering Equation Solver (EES) software has been used to perform parametric analysis on different types of static mixers. A range of viscosity values was used to calculate the pressure drop across the length of the static mixer. It is important to note here that the gas/polymer solution will have a lower viscosity than a pure polymer in the actual experiment. The pressure loss is highest for GX-type static mixer sold by Stamixco.inc shown in Fig. 3. A higher degree of mixing is possible with the GX-type static mixer compared to a helical static mixer. The minimum length of the static mixer cannot be less than $20 \mathrm{~cm}$. As multiple ports need to be drilled into the wall of the static mixer chamber, shorter tubes are more likely to warp during the drilling process. The extruder's maximum pressure limit is $45 \mathrm{MPa}$ and the maximum pressure loss for a $16.5 \mathrm{~cm}$ helical static mixer is $5 \mathrm{MPa}$ at 3000 Pa.s viscosity (Fig. 3). Hence, the maximum possible pressure loss for a helical static mixer is within acceptable range. The acceptable pressure loss range for the GX type mixers is at viscosity levels below 1000 $\mathrm{Pa}-\mathrm{s}$. Helical static mixers can be safely operated at higher polymer viscosity composites without rupturing the rupture disc on the extruder. Therefore, the static mixer will be $16.5 \mathrm{~cm}$ long with twelve helical mixing elements [8].

Stamixco manufactured the static mixer chamber. It was designed to meet all the engineering requirements for PBAbased extrusion foaming (Fig. 4). The static mixer assembly comprises of three sections: gas injection; homogenization; foam extrusion (Fig. 5). The static mixer pipe thickness was determined according to ASME section 8 division II pressure vessel code. The maximum operating temperature is $200^{\circ} \mathrm{C}$, which serves well for polypropylene (PP) foam production. The maximum allowable pressure according to Stamixco's analysis is $31 \mathrm{MPa}$. The pipe is made of $17-4 \mathrm{PH}$ stainless steel with ID = $1.9 \mathrm{~cm}$. The static mixer is $13.5 \mathrm{~cm}$ long with 12 helical mixing blades.

a) Gas Injection Section: In the aft section of the static mixing chamber, supercritical $\mathrm{CO}_{2}$ gas will be injected into the polymer melt through an injection port. The port was designed for a 1/8 NPT check valve. The spring activated check valve will be screwed into the injection port to prevent back flow. This will stop molten polymer from getting into the injection tube and "freezing". The check valve cracking pressure will be set higher than the maximum operating pressure of the extruder to eliminate the possibility for back flow into the injection pipe.

b) Homogenizing Section: In this section of the static mixer chamber, twelve helical blades are used to dissolve the $\mathrm{CO}_{2}$ gas into the polymer melt. A single-phase polymer-gas solution is necessary for obtaining fine-celled microcellular foam. Helical blades are a popular design with lower pressure drop compared to more complex shaped mixing blades. The helical blades are manufactured by twisting metal strips or by machining a single piece of solid rod. Advanced machining techniques has allowed for smaller diameter helical blades, which are ideal for high-pressure applications. Each blade is $1.65 \mathrm{~cm}$ wide and $2.86 \mathrm{~cm}$ long. The blades are welded together in a series, and each blade is oriented at a $90^{\circ}$ offset from the blades on either side. This offset splits the polymer flow toward the radial direction increasing the degree of mixing. The contours of the helical blades generate shear fields to dissolve the gas bubbles into the polymer matrix.

The temperature within the barrel of the static mixer must be maintained above the melting temperature of the polymer. In real test conditions, the temperature within the barrel of the mixer will be kept at the $\mathrm{CO}_{2}$ saturation point for a given mixing pressure. This will ensure that the maximum possible amount of $\mathrm{CO}_{2}$ can be dissolved into the polymer. Higher concentration of $\mathrm{CO}_{2}$ dissolved within the mixture creates higher cell density in the final foamed product. Three Mica band heaters with an output of 200 watts can maintain the surface temperature of the static mixture above $400^{\circ} \mathrm{C}$. Band hater output will be controlled using a $\mathbf{J}$ type thermocouple in a closed-loop feedback. One inch thick insulation will be placed between the band heaters to maintain the correct temperature profile. The insulating material is made from silica aerogel with thermal conductivity value of $35(\mathrm{~mW} / \mathrm{m} . \mathrm{K})$ at $300^{\circ} \mathrm{C}$.

c) Cooling Section: The cooling shell on the static mixer is an integral part of the overall cooling system design. The inlet and outlet ports are positioned in a manner to make the cooling shell a parallel flow heat exchanger shown in (Fig. 6). Channels on the static mixer wall (ribbed section) increase the overall surface area to promote high rate of heat transfer. The cooling fluid flows from the inlet port and gradually flows through each of the channel before exiting through the outlet port. It is not necessary for the cooling fluid to be pressurized because the flash point of engine oil is over $200^{\circ} \mathrm{C}$. The operating temperature of the oil will be well below this point minimizing the presence of any combustible vapor.

The polymer melt cooler consists of an air-cooled radiator, hydraulic oil pump, throttling valve, 1/4" hydraulic tubing, and two $12 \mathrm{~V}$ DC power supply (Fig. 6). The two power supply unit provide the same voltage but different current according to the maximum current rating of the radiator fan and the oil pump. The pump can supply cooling oil at a maximum rate of $1.51 / \mathrm{min}$ to the cooling shell. The flow rate can be reduced with the aid of a throttling valve if needed. The air cooled radiator can cool the return fluid from the static mixer as high as $100^{\circ} \mathrm{C}$ using a fan capacity of $266 \mathrm{CFM}$. Two thermocouples will be used to

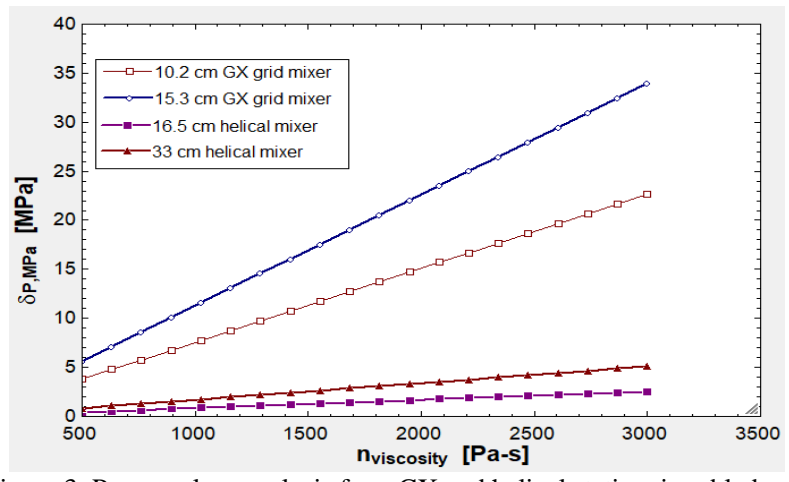

Figure 3. Pressure loss analysis for a GX and helical static mixer blades. 


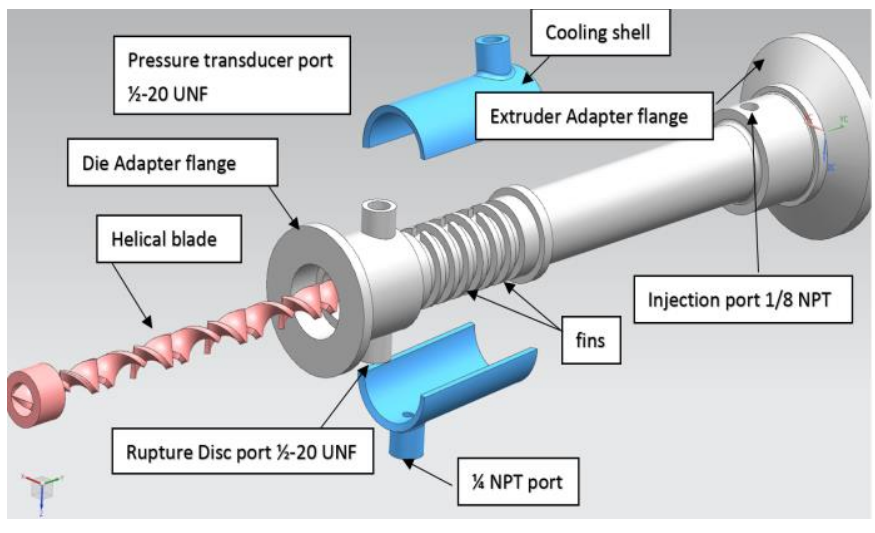

Figure 4. Exploded view of the static mixer chamber assembly.

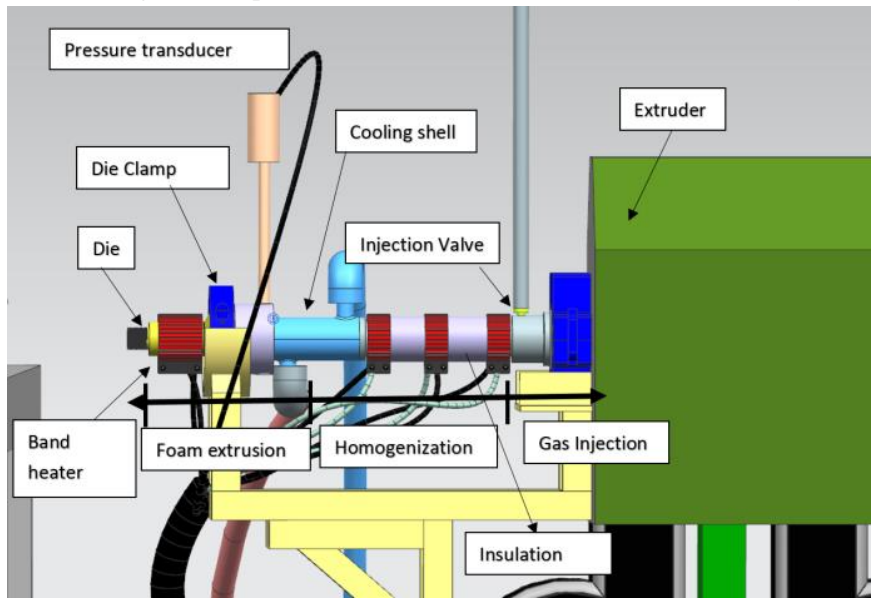

Figure 5. Full assembly arrangement of the static mixer chamber.

monitor the oil temperature at the inlet and the outlet ports. If the return fluid temperature is above $110^{\circ} \mathrm{C}$, a safety switch will be triggered to shut down the pump. A manual emergency switch has been integrated into the system to shutdown operation if a leak is present. The whole system can be turned on and off using the green switch during normal operation (Fig. $6)$.

a) Extrusion Section: The single-phase solution will experience rapid pressure drop as it flows out of the die nozzle opening. This will initiate phase separation within the mixture and the polymer melt will start to foam and fill the mold cavity. The interior contours of the die channel the gas laden polymer melt toward the opening seen in Fig. 7. The die opening is $3 \mathrm{~mm}$ and the length is $100 \mathrm{~mm}$. It has been designed to deliver the polymer foam inside a cylindrical mold. The overall pressure drop inside the die was determined from ANSYS Polyflow software package for polyethylene melt. It was determined from the analysis that with a maximum melt flow rate of $5 \mathrm{~kg} / \mathrm{h}$ and $1000 \mathrm{~Pa}$.s die inlet viscosity, the maximum pressure drop from the inlet to the outlet is $30 \mathrm{MPa}$ as seen in Fig. 8.

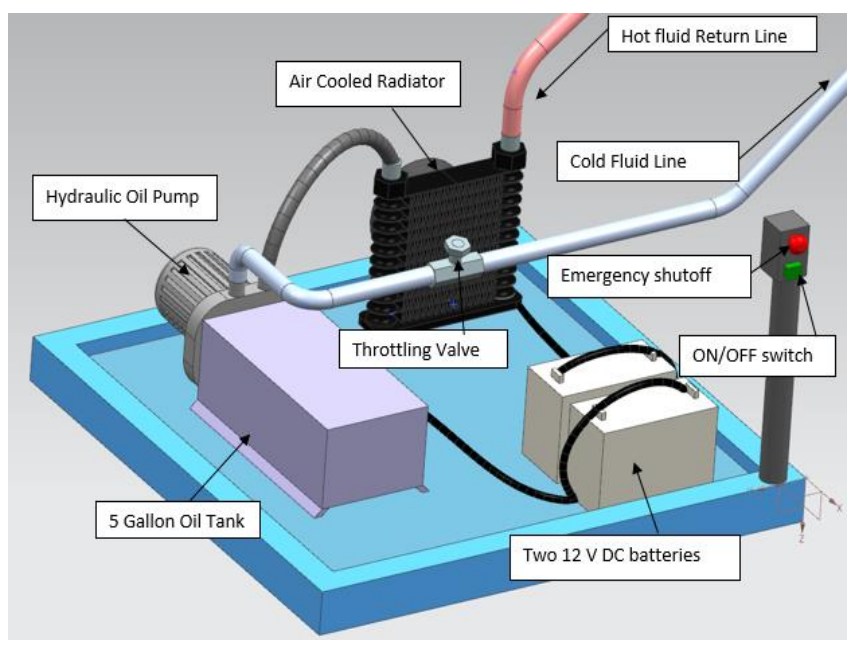

Figure. 6. Polymer melt cooler assembly.

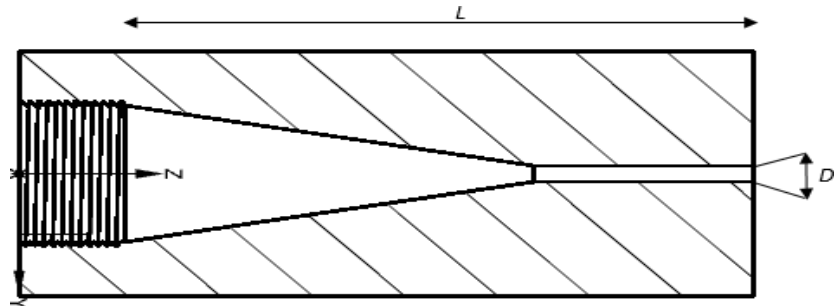

Figure. 7. Die geometry for PBA foam extrusion.

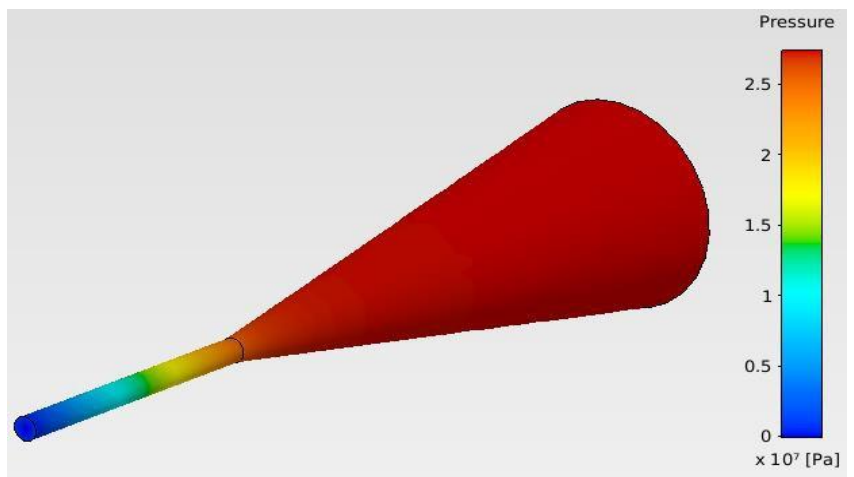

Figure. 8. Pressure loss along the die length.

\section{CONCLUSION}

The presented experimental setup was designed to produce polyolefin foam with PBA for RRFM process. The new setup was selected for having fewer design and fabrication complexities compared against the alternative proposals. In this unique design, the PBA is directly injected into the mixing chamber rather than the extruder barrel. The gas/polymer solution will be produced inside the static mixer. It has been shown, that helical static mixers are suitable for polymer foaming application for having significantly lower pressure loss. The new experimental setup could lead to developing breakthrough processing concepts that would be capable of fabricating new classes of ultra-low-density rotationally molded integral-skin cellular composites. 


\section{REFERENCES}

[1] L. Beall, "The Rotational Molding Industry," in Rotational Molding Design Materials, Tooling, and Processing, Cincinnati, Hanser/Gradner Publications, 1998, ch. 1, pp 22-23.

[2] S. Semerdjiev, Structural Foam, Society of Plastics Engineer, 1982, ch 1 pp.1-2.

[3] R. Pop-Iliev, 2011, "Processing of integral skin cellular polymeric composites in rapid rotational foam molding," Acta Physica Polonica A, Vol. 120, No. 2, Aug. 2011, pp. 292-297.

[4] R. Pop-Iliev, et. al., 2014, US Patent No: 8,628,704 B.

[5] S. Siripurapu, Y. Gay, J. Royer, J. DeSimone, R. Spontak, and S. Khan, "Generation of mirocellular foams of PVDF and its blends using supercritical carbon dioxide in a continuous process," Polymer, vol. 43, pp. 5511-5520, 2002.

[6] M. Sauceau, J. Fages, A. Common, C. Nikitine, and E. Rodier, "New challenges in polymer foaming: Areview of extrusion processes assisted by supercritical carbon dioxide," Progress in Polymer Science, vol. 36, pp. 749-766, 2011.

[7] C. Park, and N. Suh, "Rapid Polymer/Gas Solution Formation for Continuous Production of Microcellular Plastics," Journal of Manufacturing Science and Engineering, vol. 118, pp. 639-645, November 1996.

[8] Gottlieb Schneider, "Static Mixing Technology For Extrusion and Injection Molding," Stamixco Ltd., CH-8404 Winterthur /SWITZERL. 